\title{
Research on Adjustment of Price of Construction Materials Caused by Price Changes
}

\author{
Ke Zhao \\ Department of Industrial Engineering, Tianjin University of Technology, Tianjin, 300384, China. \\ 2694933309@qq.com
}

Keywords: Price changes; Changes in the price of construction materials; price adjustment; Risk sharing.

\begin{abstract}
In construction projects, changes in the price of construction materials caused by changes in prices often lead to adjustments in the contract price. However, these adjustments have not yet established a unified adjustment plan among the contracting packages. As a result, they may cause the occurrence of contract disputes and may even cause the project to fail. Based on this, this study takes the change in price of building materials caused by changes in prices as the research object, determines the scope of the main building materials of the construction project in combination with the case, and classifies the building materials that can be adjusted for prices on the basis of the analysis of relevant documents. On the basis of a clear range of price-adjustable materials, in the end, this paper proposes the use of bidding strategies to reduce the risk of changes in the price of construction materials faced by contractors, and conducts research on a given project of bidding documents to determine appropriate bidding strategies. Take measures from the source to minimize the risk caused by changes in prices, and conduct a reasonable risk sharing program.
\end{abstract}

\section{Introduction}

From the development trend of the construction industry, the funds occupied by construction materials are about $60 \%$ of the total project cost [1]. At the same time, the project projects are characterized by a long period, so when the market price of building materials changes When the magnitude is too large, it is bound to have a major impact on the cost of the project [2]. The change in material prices has led to the growth rate of the total project cost exceeding the general profit rate of construction companies. Under such circumstances, if the contractor's price changes due to price changes are not reasonably compensated, it will inevitably lead to difficulties for the contractor's cash flow and increase the company's cost. If the contractor cannot obtain reasonable compensation, it may be Bad results such as stoppages, disputes, or project failures.

\section{The Necessity of Determining the Scope of Adjustable Building Materials}

In the actual case, the defects and deficiencies of the construction contract itself, such as the inadequacy of the agreed adjustment scope of the risk and the terms of the price adjustment boundary, etc., will cause a lot of controversy in the contract price, and the two parties will refuse to yield to each other. If negotiation fails, the settlement contractor's long delay cannot bring serious impact to both parties. Therefore, the construction contract is the carrier for the rights and obligations of both sides of the contract. It is the evidence that both parties need to comply with. Therefore, when the construction contract is formulated, the type and scope of the price adjustment materials and the contract should be specified in the special terms of the contract. The basis for compliance with price adjustments, etc., is clearly stipulated so that it not only complies with laws and regulations, but also protects the interests of both sides of the contract and the package, and serves as a basis for adjustment of prices in response to material price changes.

If the contractor and the contractor conclude the contract, the contractor and the contractor shall stipulate the scope of the adjustment in the terms of the contract in order to avoid the occurrence of subsequent contract price disputes due to the incompleteness of the terms of the contract and affect the successful completion of the construction project. As well as adjusting the range and other factors 
[3]. After the above contract is concluded, the contractor's interests are guaranteed at the source, eliminating the contractor's concern about the risk of price changes, and focusing more on the quality and progress of the project's construction, and ultimately the quality and quantity of the project. The project was transferred to the construction unit and the final settlement was successfully completed. Therefore, for the price adjustment of materials caused by the price of material changes, we must first clarify the type or range of price-adjustable materials.

\section{Division of Adjustable Price Building Materials}

The contractor and the contractor shall agree on the scope of the price adjustment material and the price adjustment limit when the price changes are concluded. If the agreement is not clear, it will leave hidden troubles for the price disputes in the later construction process. As an important factor leading to disputes, it has a serious impact on whether the project can proceed smoothly. After the conclusion of an agreed contract, the legal binding force of the agreed terms of the contract provides the contractor with the guarantee that it can concentrate its energy on the quality and progress of the construction of the project without having to worry about the impact of price change risks on it. It can be seen that when studying the issue of material price adjustment, the first task is to clarify the range of materials that can be tuned [4].

Through case analysis, the scope of the main building materials of the project is deduced: those materials whose material costs are ranked in the order of 0 to $80 \%$. The change in the price of these construction materials has a great influence on the contract price and can be regarded as the main material of the construction project. Through the study of the cost documents of all provinces and cities and literature research, combined with the analysis of the proportion of material costs in the actual project using Pareto analysis method, the range of materials available for price adjustment can be determined by referring to the following three methods.

(1) Determination of the proportion of the material fee according to the material fee

For example, non-major building materials are those materials whose material price accounts for less than $1 \%$ of the unit engineering fee; materials whose percentages are between $1 \%$ and $10 \%$ are called one type of main material; and two types of main materials are those More than $10 \%$ of all types of construction materials with material costs.

(2) Determined by professional project

1) Construction Engineering: Concrete, steel, cement, sandstone, bricks, blocks, etc.

2) Decoration engineering: glass, stainless steel, stone, block, wood, paint, metal components, wallpaper wall coverings, floors, ceiling panels, etc.

3) Installation engineering: all kinds of cables, pipes, wires, distribution boxes, meters, radiators, large-scale equipment, etc.

4) Municipal engineering: asphalt concrete, steel materials, drainage pipes, concrete, cement, wood, bridge bearings, joints, stone, precast, cast-in-place concrete, asphalt products, etc.

5) Landscape engineering: all kinds of seedlings, steel, ancient building materials, commercial concrete, commercial mortar, wood, stone, sand, cement, etc.

6) Mine engineering: steel, cement, concrete, wood, steel pipes, brackets, etc.

\section{Research on the Influencing Factors of Price Risk of Adjustable Price Building Materials}

\subsection{Influence Factors of Risk Control Capability}

The comprehensive strength of the contractor and the contractor is the key to determining risk sharing[5]. It is a decisive factor in the formation of control capability. The game of the combined strengths of the two parties and the contracting party dominates the changes in the ratio and magnitude of risk sharing, and affects the ability and effectiveness of risk control[6]. The higher the index, the stronger its risk control ability. The current construction market phenomenon of "big bullying and offending" is common. The risk sharing between the contractor and the contractor is essentially a comparison of the strengths of both parties. When the contractor's comprehensive strength is strong, and the bidders are numerous and their strengths are weak, , It is easy to form a buyer's market. At 
this time, the risk is often borne by the contractor. When the contractual manpower period is tight and the investment management is loose, resulting in weaker performance, the contractor's competitive facet performance is stronger. At this time, it is the seller's market, and the risk is often tilted toward the contractor. This paper points out that the risk control capability indicators mainly include: the depth of knowledge of risk, risk management techniques, risk management level and experience, as shown in Figure 1.

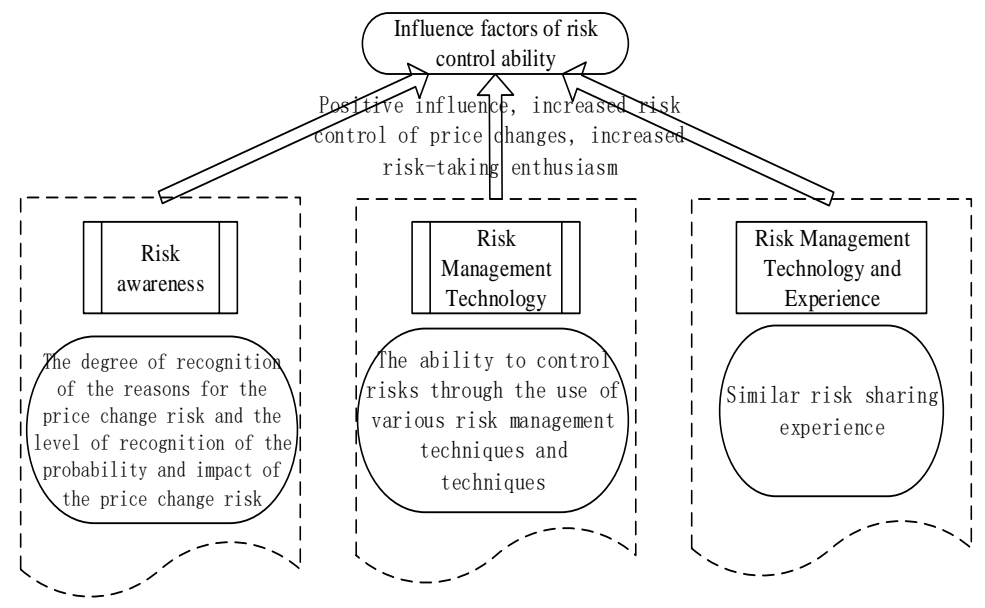

Fig. 1. Analysis of the Fluencing Factors of Risk Control Ability

\section{Source: Self-draw}

\subsection{Risk Management Costs and Benefits}

In carrying out risk sharing, we must have the principles of responsibility, power, and interest. The occurrence of risk inevitably brings certain losses to various stakeholders[7]. If the party with a relatively large loss will generally want to avoid the risk, the subject will have a greater willingness to sign a reasonable contract. Risk sharing. Figure 2 below shows the analysis of risk management costs and benefits.

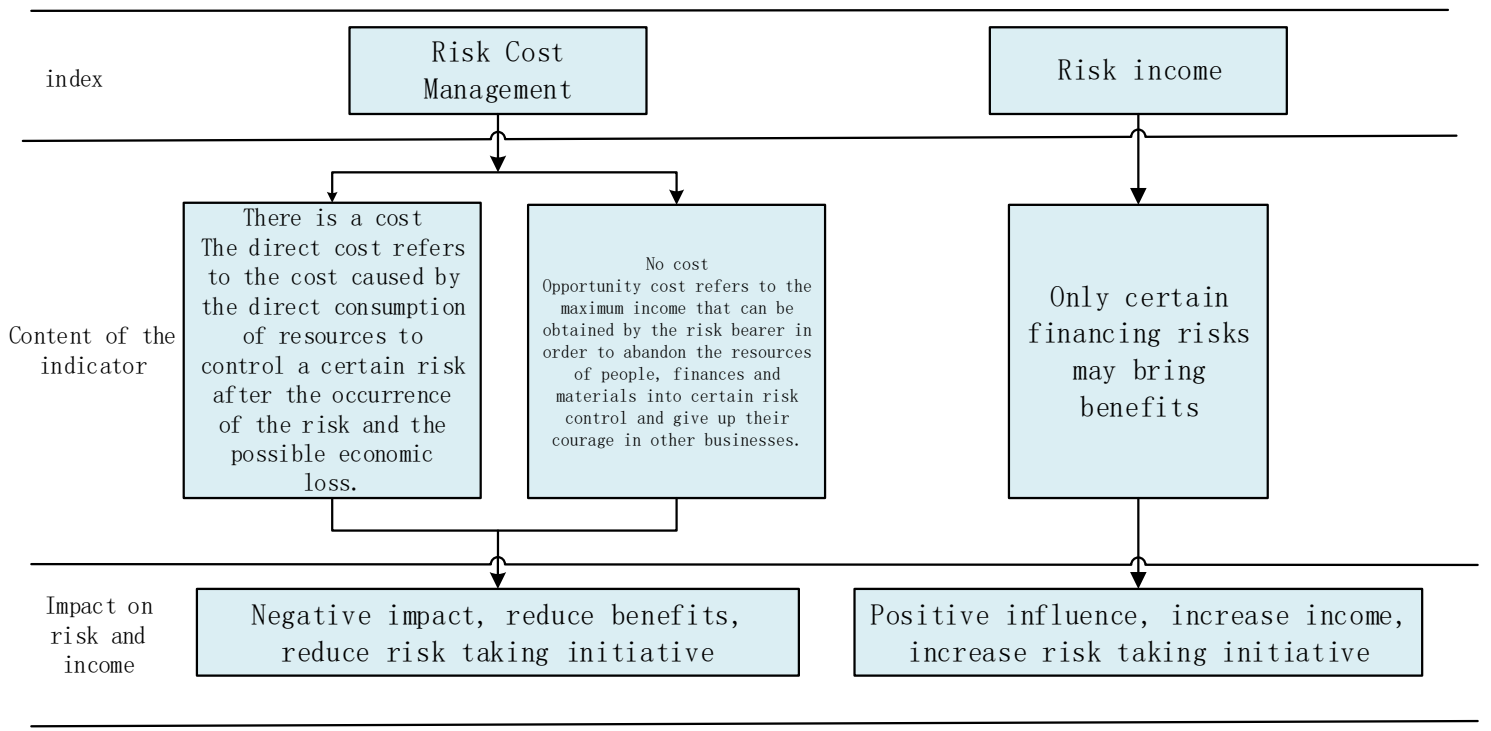

Fig.2. Analysis of the Influence of Risk Management Cost on Benefits

\section{Source: Self-draw}

\subsection{Influence Factors of Risk Bearing Capacity}

The risk bearing capacity indicators mainly reflect the ability of the contracting parties to bear the losses caused by the risks. The ability of the project participants to bear the risks caused by the risks 
is generally examined through two aspects: risk reserve ratio and profitability. The analysis is shown in Figure 3.

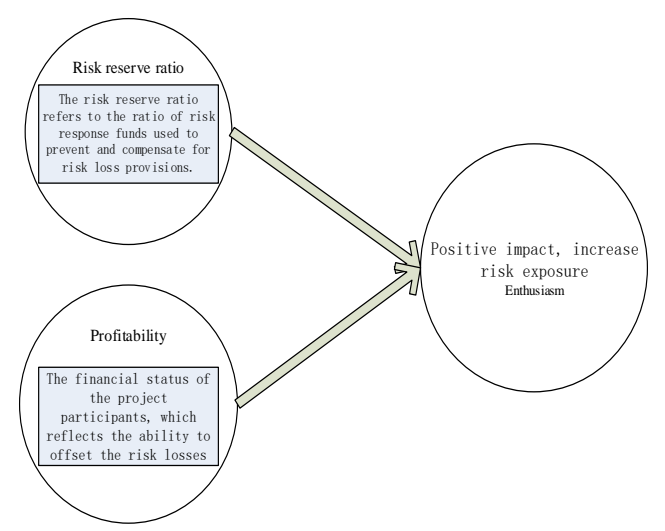

Fig.3. Analysis Diagram of Impact on Risk Bearing Ability

Source: Self-draw

According to the 13th edition of the "List Price Pricing Regulations" stipulations on price changes, and with the guidance of various provinces and cities and other specific circumstances, it is concluded that: When the supplier of materials is the contractor, both parties in the contract concluded in the risk sharing The principle is to pre-agree on the scope of the range of adjustable price materials and the range of adjustments; if there is any situation that the two parties have not agreed in advance, the boundary shall be adjusted in accordance with $5 \%$, and the risks within the contractor shall not be adjusted by the contractor's price, and other risks shall be attributed to The contractor will adjust the price according to the specific circumstances.

\subsection{Willingness to Take Risk Influence Factors}

The principle of "willingness to take risks" means that project participants have the greatest preference for risk and have the incentive to take risks. The risk appetite indicator is comprehensively measured by three indicators: risk appetite, risk acceptance incentive, and decision motivation. They are all positive indicators. As shown in Table 1.

Table 1. Indicators and impact of willingness to risk

\begin{tabular}{|c|c|c|}
\hline Index & Content of the indicator & Impact on willingness to take risks \\
\hline Risk preference & $\begin{array}{c}\text { The attitude and tendency of the } \\
\text { project risk sharer in the face of } \\
\text { uncertain risks }\end{array}$ & $\begin{array}{c}\text { The greater the value of the indicator, the } \\
\text { stronger the willingness of the participants to } \\
\text { bear this risk }\end{array}$ \\
\hline $\begin{array}{c}\text { Acceptance of } \\
\text { risk incentives }\end{array}$ & $\begin{array}{c}\text { If given some incentives, risk takers } \\
\text { are more willing to take risks or } \\
\text { reduce risk }\end{array}$ & $\begin{array}{c}\text { The larger the index value, the more obvious } \\
\text { the incentive effect and the higher the } \\
\text { willingness to take risks }\end{array}$ \\
\hline $\begin{array}{c}\text { Decision } \\
\text { motivation }\end{array}$ & $\begin{array}{c}\text { Risk-sharing participant's basic } \\
\text { motivation when making a decision } \\
\text { to take a risk }\end{array}$ & $\begin{array}{c}\text { The indicator itself does not have positive and } \\
\text { negative attributes }\end{array}$ \\
\hline
\end{tabular}

Source: Self-drawn

\section{Price Change Contractor's Tender Offer Strategy}

In actual price sharing, owners often do not take direct incentives to achieve reasonable risk sharing. Instead, risk incentives are implemented by increasing the risk costs contained in the quotation, in order to reveal the various parts of the contractor's price. In this paper, the contractor's quotation is divided into two parts: cost plus normal profit and risk premium. The owner often needs to transfer the risk to the contractor. Then the owner must pay the corresponding reward, and the contractor will be willing to bear the risk[8]. If the risk premium cannot meet the contractor's compensation for the corresponding risk, the contractor will refuse to accept the risk. Especially when the proportion of risk sharing has been determined, whether the contractor accepts the risk or not, the size of the incentive becomes an important factor in making a decision, but in practice the incentive 
is often affected by other factors, such as the degree of risk preference and the contractor's strategy. Wait. The adjustment of the corresponding price under the risk of price fluctuations is the problem of the quotation strategy in the actual quotation.

The realistic conditions for contractors to use bid strategies to achieve material price adjustments are: (1) The bidding documents clearly show that the economic risk caused by price changes should be compensated in a timely manner so that the contractor will not calculate all the risks in the quotation when determining the bid price, so that the bidders can propose more. For competitive bid quotations, bidders can use the principle of reasonable sharing of risks between two parties to organize unbalanced quotations. (2) Experienced contractors predict that material price changes may occur during the construction process of the project, which is the opportunity for the contractor to adopt a bid strategy[9]. The main bidding strategy is shown in Figure 4.

Bidding strategy

\begin{tabular}{|c|c|}
\hline $\begin{array}{l}\text { Survival } \\
\text { strategy }\end{array}$ & $\begin{array}{l}\text { The bidding enterprise has caused a crisis of survival } \\
\text { due to certain reasons. In order to survive, the company } \\
\text { adopts an unprofitable loss quotation and does not } \\
\text { consider other influencing factors to win the bid. }\end{array}$ \\
\hline $\begin{array}{c}\text { Competitive } \\
\text { strategy }\end{array}$ & $\begin{array}{l}\text { When bidding companies try to enter a new region to } \\
\text { undertake projects and local competitors are more } \\
\text { powerful or their own operating conditions are sluggish, } \\
\text { they should fully estimate the competitors' bidding } \\
\text { strategies on the basis of accurately calculating costs } \\
\text { in order to open up markets, Low profit as the goal, } \\
\text { using a low-cost guaranteed quote to win the winning bid }\end{array}$ \\
\hline $\begin{array}{c}\text { Profitable } \\
\text { strategy }\end{array}$ & $\begin{array}{l}\text { When the bidder has opened up the situation in a certain area, } \\
\text { has saturated construction capacity, high credibility, few } \\
\text { competitors, and has technical advantages, and the construction } \\
\text { project is difficult and the schedule quality is demanding, a } \\
\text { high profit and high bid can be used to win more for the } \\
\text { company. Profit quote strategy }\end{array}$ \\
\hline
\end{tabular}

Fig. 4. The main bidding strategy

\section{Summary}

This article mainly focuses on the price changes that often occur at the current stage as the starting point of the study. It studies the price adjustment problems caused by changes in the price of materials caused by price changes, conducts research through relevant literature, and conducts research on the construction industry in response to price changes in various provinces and cities. The rules and guidelines issued in response to the impact of the reforms led to the conclusion that when contractors and contractors reduce the price adjustment disputes caused by price changes, they must first clarify the range of price adjustment materials and the range of price adjustments, and Starting from the point of view of the contractor, he pointed out that in order to minimize the risks brought about by price changes, it is of great significance for the contractor to do preventive work in advance to reduce disputes caused by price changes.

According to the range of adjustable price materials obtained from the previous phase analysis and the range of adjustment, the contractor shall review the quotation requirements, project quantity list, and other contents of the tender documents provided by the tenderer in combination with their own similar project bidding experience in the review project. Based on the quantity, it is of great significance to propose an appropriate bidding strategy that does not greatly satisfy the tenderer's acceptance scope. 


\section{References}

[1]. Xing Shiyong. Research on price adjustment of fixed price contract project caused by abnormal price fluctuation [D]. Tianjin: Tianjin University of Technology, 2012.

[2]. He Yuanyuan. Research on Settlement Dispute Caused by Abnormal Price Fluctuations under the Contract of Total Price [D]. Tianjin: Tianjin University of Technology, 2013.

[3]. Lu Xiaochun, Li He, Yin Yilin, Xing Shiyong. The legal basis and treatment of price adjustment of fixed price contract project caused by abnormal price fluctuation[J]. Project Management Technology, 2012(6):56-60.

[4]. Guo Kaiyin. Research on project price management system [D]. Tianjin: Tianjin University of Technology, 2011.

[5]. Xiong Wei. Price fluctuations and countermeasures for main materials of traffic construction projects[J]. Hefei. Engineering and Construction, 2009, 23(4): 580-581.

[6]. Yin Yilin, Zhao Hua. Study on risk sharing measurement of engineering projects: model construction, scale compilation and validity test [J]. Forecast, 2013, (4): 8-14. [7] Additions to prevent deflation Ensuring Economic Growth[J].China National Conditions,2009(4):12-14.

[7]. Du Yaling, Yin Yilin. Research on Risk Sharing Framework of Engineering Project from the Perspective of Incomplete Contract[J]. Journal of Chongqing University(Social Sciences Edition),2012(1):65-70.

[8]. He Ruening. Management of materials provided by contractors in project construction [J]. Engineering Design and Research,2012(2):45-46.

[9]. Su Zhilong. Identification and prevention of unbalanced bids for project bidding[J]. Guangzhou Architecture, 2006(2):40-42. 